Bull. Mater. Sci., Vol. 21, No. 3, June 1998, pp. 257-261. (C) Indian Academy of Sciences.

\title{
Density of micro-quantity liquids by the method of rise of drops in immiscible liquids
}

\author{
G J SRINIVASAN*, G THIRUNAVUKKARASU ${ }^{\dagger}$ and P SATYANARAYANA ${ }^{\dagger}$ \\ Department of Electronics and Instrumentation, St. Peter's Engineering College, Avadi, Chennai 600 054, India \\ ${ }^{\dagger}$ Physics Division, Forensic Sciences Department, Chennai 600004 , India
}

MS received 12 January 1998; revised 18 April 1998

\begin{abstract}
The conventional methods such as specific gravity bottle method, pyknometer method, and the Westphal-balance method or the capillary tube method where accurate weighing is a problem cannot be employed when liquids are available in micro-quantities. The method described may be employed to determine the density of micro-quantity liquids (even up to $0.5 \mu \mathrm{l}$ ) and it is found to be simple and rapid. The method also allows the analyst to retrieve the sample for further analysis.
\end{abstract}

Keywords. Density; micro-quantity liquids; rise of liquid drops; immiscible liquid column.

\section{Introduction}

Studies on the rise of liquid drops through an immiscible liquid column have been carried out by several authors (Klee and Treybal 1956; Saffman 1956; Bhattacharya and Venkateswarlu 1957; Houghton et al 1957; Harmathy 1960; Goldsmith and Mason 1962; Griffith 1962; Davis and Acrivos 1966; Zieminski and Raymond 1968; Grace et al 1976; Clift et al 1978). Srinivasan et al (1996) have previously dealt with the problem of rise of liquid drops with six variables, $F, D, u, \sigma, \eta$ and $\rho$ alone $(F$, drag force; $D$, diameter of the liquid drop, $u$, terminal velocity acquired by the liquid drop; $\eta$, viscosity of the liquid in the column, $\rho$, density of the liquid drop; $\sigma$, density of the liquid in the column), to arrive at an expression for the drag force, $F$ acting on the drop in rise through the method of dimensions. It has been suggested that the simple expression for the constant quantity, $S$ occurring in the process of simplification of the drag force expression, $F$ may be used to determine the density, $\rho$ of the liquid drop.

The expression for the density, $\rho$ obtained (Srinivasan et al 1996) is

$$
\rho=\left\{(2 \sigma+\lambda)-[\lambda(\lambda+4 \sigma)]^{1 / 2}\right\} / 2,
$$

where

$$
\begin{aligned}
& \lambda=S^{2} \eta /(r / u)^{3}, \\
& S=\left[(r / u)^{3 / 2}(\sigma-\rho)\right] /\left[\eta^{1 / 2} \rho^{1 / 2}\right],
\end{aligned}
$$

$r$ being radius of the drop.

\footnotetext{
*Author for correspondence
}

The physical property, density assumes a position of great importance in the identification of pure liquids. When liquids are available in bulk quantities, conventional methods like specific gravity bottle method, pyknometer method, Westphal-balance method etc may be employed to determine this physical constant. When liquids are available in small quantities and when neither the conventional methods nor the capillary tube method (where weighing is a problem) is adoptable, a new method has to be developed to determine the density of the micro-quantity liquids.

In the present paper, therefore, the method and the expression for $\rho$ suggested earlier (Srinivasan et al 1996) have been employed to determine the density, $\rho$ of liquid drops and the results obtained have been presented.

\section{Experimental}

\subsection{Equipment and liquids used}

A long graduated glass cylinder (of internal diam. 0.05 $\mathrm{m}$ and height $1.5 \mathrm{~m}$ ) with a small side tube attached to it at the bottom and sealed with a rubber septum (figure 1); stop watch (Racer), accurate to $0.05 \mathrm{sec}$; Hamilton precision syringe, accurate to $0.01 \mu \mathrm{l}$; Ethylene glycol and soap oil (Ranbaxy purified grade); Hexane, Heptane, MIBK, Xylene, Cyclohexane, Benzene, Toluene, Iso-amyl acetate (Fisher purified grade); Turpentine (Chemlab purified grade); Water, Petrol, Kerosene, Naphtha and Diesel (distilled); Palm oil, Groundnut oil and Gingely oil (KKR refined grade); Coconut oil (VVD refined grade); Castor oil (Richardson refined grade); Sandalwood oil (Vibhav purified grade), were used (table 2). 


\subsection{Method}

The liquids viz. ethylene glycol, water, chlorobenzene and bromobenzene, which were immiscible with the corresponding drop liquids (table 2) were selected as column liquids and used for filling the cylindrical column. Liquid drops of known volume were gently injected at the bottom of the liquid column using a graduated Hamilton Precision micro-syringe. When the drop rised freely and vertically without oscillation, the terminal velocity, $u$ was determined by observing the time, $t$ required by the liquid drop of radius, $r$ to cover the

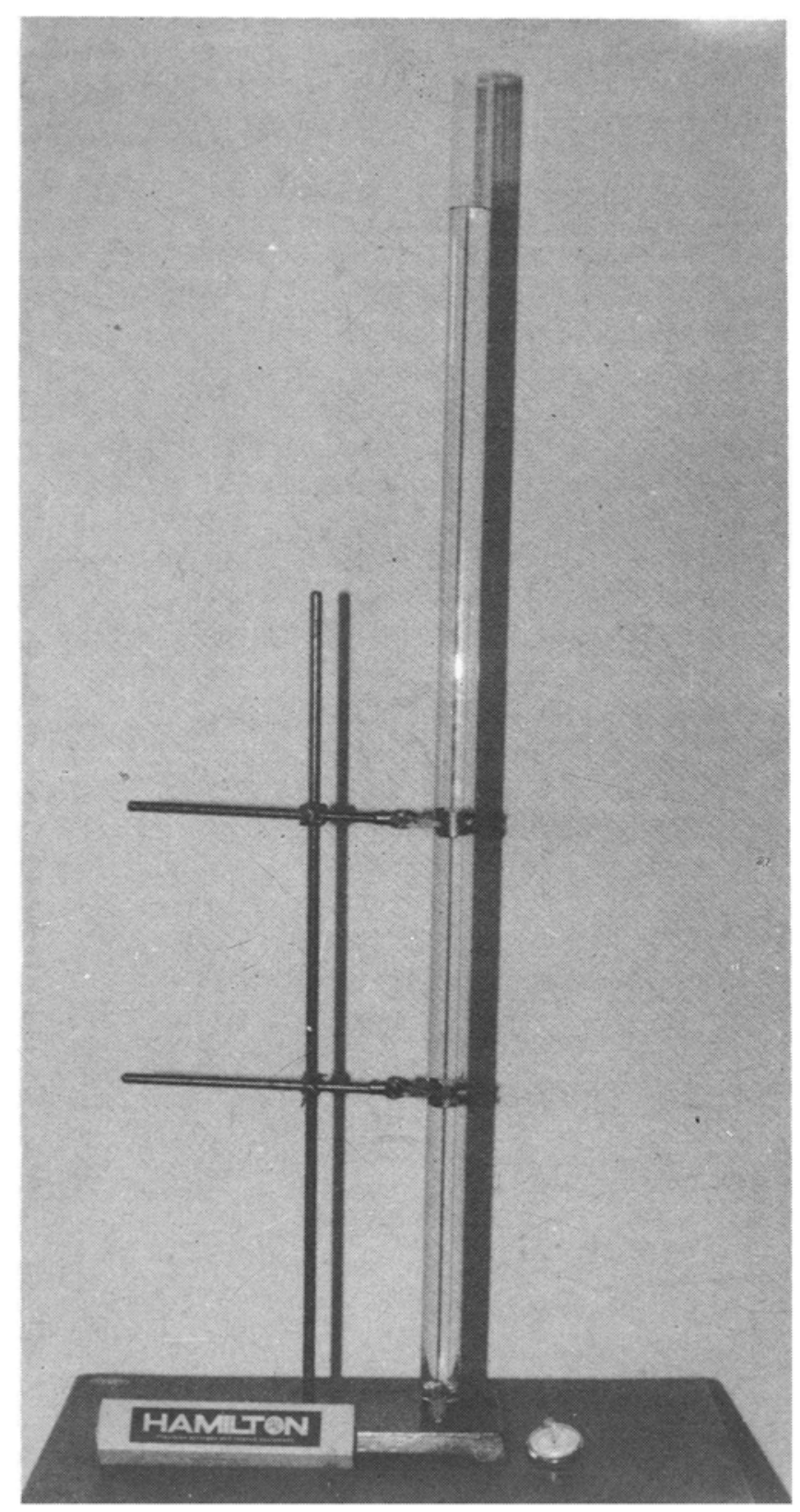

Figure 1. The set up used for conducting rising drop experiments. distance, $d$ between two graduations on the column. Assuming the rising drop to be a sphere of volume, $V$ of diameter, $D$ then the drop radius was obtained from $r=(3 V / 4 \pi)^{1 / 3}$, where $r=D / 2$. All the experiments were conducted at room temperature $\left(25^{\circ} \mathrm{C}\right)$.

\section{Results and discussion}

The data presented in table $I$ for ten liquid drop-liquid pair systems having three data points each shows that $r / u$ is approximately constant. The other seventeen liquid drop-liquid pair systems (table 2) for which the experimental results have been obtained satisfy the same. The density of the column liquids and the drop liquids, viscosity of the column liquids, interfacial tension between the liquid drop and liquid column given in table 2 were determined by the specific gravity bottle method, Ostwald Viscometer and the method of drops, respectively. The values of $(r / u)^{3 / 2} / \eta^{1 / 2}, \rho^{1 / 2} /(\sigma-\rho)$, and $S$ are given in table 3. Table 4 furnishes the observed density of the liquids (refer table 2) and the density of liquids determined from (1) and the estimated error in percentage. It may be seen from table 1 that for liquid drops of different radii of a given liquid pair system, $r / u$ is a constant. The value of $S$ calculated from (3) has been found to be approximately constant for all the liquid dropliquid pair systems (table 3) and its mean value is $0.313366 \mathrm{~m}^{-1} \mathrm{~s}^{2}$ (table 3). This mean value of $S$ is also found to be approximately equal and agree to the experimental mean value of $S\left(0.3176 \mathrm{~m}^{-1} \mathrm{~s}^{2}\right)$ predicted previously for the thirteen liquid drop-liquid pair systems (Srinivasan et al 1996). The density values of the liquid drop estimated from (1) (column 4, table 4) using the experimental mean value of $S\left(0.313366 \mathrm{~m}^{-1} \mathrm{~s}^{2}\right.$; table 3$)$, $r / u$ (table 2) and $\eta$ (table 2) show that they are comparable with the observed density value of the liquids determined by the specific gravity bottle method (column 3, table 4). The estimated error in percentage (column 5, table 4) is found to be less than $0.5 \%$ between the observed and the calculated density values (table 4).

Since by knowing the radius, $r$ of the liquid drop and the terminal velocity, $u$ attained by it in the liquid column, one may determine the density of the liquid drop from (1) with the experimentally predicted mean value of $S\left(0.313366 \mathrm{~m}^{-1} \mathrm{~s}^{2}\right.$, table 3$)$ and the viscosity of the liquid in the column (table 2), the only unknown quantity to be determined being $r / u$. This may be accomplished in one or two min.

The minimum amount of liquid sample required for this method is less than $1 \mu \mathrm{l}$, and therefore this method may be adopted to determine the density of a liquid sample available in small or micro-quantities for which the density cannot be determined by any other conventional method. It also provides a solution to the analyst who prefers, as far as possible to preserve the original 


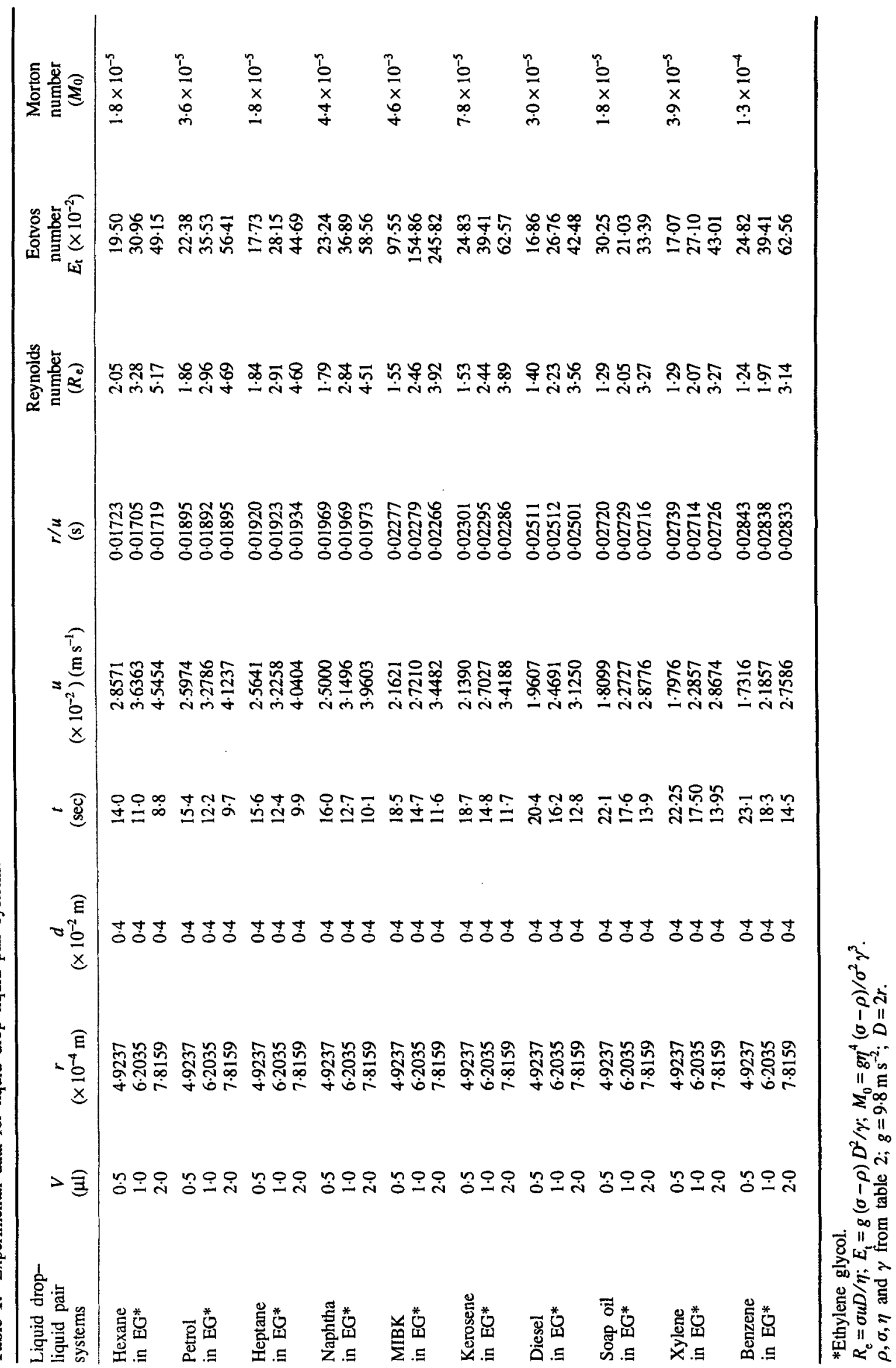


Table 2. Liquid drop-column liquid pair systems and their physical constants.

\begin{tabular}{|c|c|c|c|c|c|c|c|c|}
\hline $\begin{array}{l}\text { Sl. } \\
\text { no. }\end{array}$ & $\begin{array}{l}\text { Liquid } \\
\text { drop }\end{array}$ & Liquid column & $\underset{\left(\mathrm{kg}^{-3}\right)}{\rho}$ & $\begin{array}{c}\sigma \\
\left(\mathrm{kg}^{-3}\right)\end{array}$ & $\begin{array}{l}(\sigma-\rho) \\
\left(\mathrm{kg}^{-3}\right)\end{array}$ & $\underset{\left(\mathrm{Nsm}^{-2}\right)}{\eta}$ & $\begin{array}{c}\gamma \\
\left(\mathrm{nm}^{-1}\right) \\
\left(\times 10^{-3}\right)\end{array}$ & $\begin{array}{l}r / u \\
\text { (s) }\end{array}$ \\
\hline 1. & Hexane & EG* & $665 \cdot 12$ & 1108.00 & $442 \cdot 88$ & 0.01520 & 21.6 & 0.017192 \\
\hline 2. & Petrol & EG* & 715.38 & 1108.00 & 392.62 & 0.01520 & 16.7 & 0.018964 \\
\hline 3. & Heptane & EG* $^{*}$ & $720 \cdot 24$ & 1108.00 & 387.76 & 0.01520 & 20.8 & 0.019244 \\
\hline 4. & Naphtha & EG* & 733.29 & 1108.00 & 374.71 & 0.01520 & $15 \cdot 3$ & 0.019708 \\
\hline 5. & MIBK & EG* & 792.85 & 1108.00 & $315 \cdot 15$ & 0.01520 & $3 \cdot 1$ & 0.022752 \\
\hline 6. & Kerosene & $\mathbf{E G}^{*}$ & 797.22 & 1108.00 & 310.78 & 0.01520 & 11.9 & 0.022998 \\
\hline 7. & Diesel & EG* & $830 \cdot 65$ & 1108.00 & $277 \cdot 35$ & 0.01520 & 15.6 & 0.025111 \\
\hline 8. & Soap oil & EG* & 857.01 & 1108.00 & 250.99 & 0.01520 & 18.0 & 0.027218 \\
\hline 9. & Xylene & EG* & 857.50 & 1108.00 & 250.50 & 0.01520 & 13.9 & 0.027318 \\
\hline 10. & Benzene & EG* $^{*}$ & $870 \cdot 60$ & 1108.00 & 237.40 & 0.01520 & $9 \cdot 1$ & 0.028376 \\
\hline 11. & Palm oil & EG* & 876.66 & 1108.00 & $231 \cdot 34$ & 0.01520 & $9 \cdot 6$ & 0.028816 \\
\hline 12. & Groundnut oil & EG* & 910.91 & 1108.00 & 197.09 & 0.01520 & $12 \cdot 0$ & 0.032461 \\
\hline 13. & Gingely oil & EG* & 915.85 & 1108.00 & $192 \cdot 15$ & 0.01520 & $12 \cdot 3$ & 0.033150 \\
\hline 14. & Coconut oil & EG* & 917.27 & 1108.00 & $190 \cdot 73$ & 0.01520 & $13 \cdot 3$ & 0.033273 \\
\hline 15. & Castor oil & $\mathrm{EG}^{*}$ & $925 \cdot 72$ & 1108.00 & $182 \cdot 28$ & 0.01520 & 7.2 & 0.034431 \\
\hline 16. & Sandalwood oil & $\mathrm{EG}^{*}$ & $960 \cdot 20$ & 1108.00 & 147.80 & 0.01520 & $14 \cdot 1$ & 0.040103 \\
\hline 17. & Heptane & Water & $720 \cdot 37$ & $1000 \cdot 00$ & 279.63 & 0.00100 & $38 \cdot 7$ & 0.009765 \\
\hline 18. & Cyclohexane & Water & 775.04 & $1000 \cdot 00$ & 224.96 & 0.00100 & $20 \cdot 4$ & 0.011578 \\
\hline 19. & Kerosene & Water & $797 \cdot 34$ & $1000 \cdot 00$ & 202.66 & 0.00100 & 43.8 & 0.012480 \\
\hline 20. & Soap oil & Water & $857 \cdot 15$ & $1000 \cdot 00$ & 142.85 & 0.00100 & $34 \cdot 2$ & 0.015956 \\
\hline 21. & Xylene & Water & 857.95 & $1000 \cdot 00$ & 142.05 & 0.00100 & $29 \cdot 0$ & 0.016010 \\
\hline 22. & Turpentine & Water & 860.03 & $1000 \cdot 00$ & 139.97 & 0.00100 & 41.5 & 0.016448 \\
\hline 23. & Toluene & Water & $860 \cdot 89$ & $1000 \cdot 00$ & $139 \cdot 11$ & 0.00100 & 39.7 & 0.016543 \\
\hline 24. & Benzene & Water & $870 \cdot 78$ & $1000 \cdot 00$ & 129.22 & 0.00100 & $35 \cdot 0$ & 0.017382 \\
\hline 25. & Iso-amylacetate & Water & $882 \cdot 15$ & $1000 \cdot 00$ & 117.85 & 0.00100 & $29 \cdot 2$ & 0.018537 \\
\hline 26. & Water & Chlorobenzene & $1000 \cdot 00$ & 1097.99 & 97.99 & 0.00071 & $46 \cdot 1$ & 0.019610 \\
\hline 27. & Ethylene glycol & Bromobenzene & 1108.00 & $1492 \cdot 21$ & 384.21 & 0.00085 & $11 \cdot 2$ & 0.008580 \\
\hline
\end{tabular}

$\rho$, Density of the liquid drop; $\sigma$, density of the column liquid; $\eta$, viscosity of the column liquid; $\gamma$, interfacial tension between the liquid drop and the liquid in the column; $r$, radius of the liquid drop; $u$, terminal velocity of the drop.

$(r / u)$ : Mean experimental values. *Ethylene glycol.

Table 3. The values of $(r / u)^{3 / 2} / \eta^{1 / 2}$ and $\rho^{1 / 2} /(\sigma-\rho)$ and $S$.

\begin{tabular}{|c|c|c|c|c|c|}
\hline $\begin{array}{l}\text { Sl. } \\
\text { no. }\end{array}$ & Liquid drop & $\begin{array}{l}\text { Liquid } \\
\text { column }\end{array}$ & $(r / u)^{3 / 2} / \eta^{1 / 2}$ & $\rho^{1 / 2} /(\sigma-\rho)$ & $S$ \\
\hline 1. & Hexane & EG* & 0.018284 & 0.058232 & 0.313985 \\
\hline 2. & Petrol & $\mathrm{EG}^{*}$ & 0.021182 & 0.068123 & $0 \cdot 310938$ \\
\hline 3. & Heptane & EG* & 0.021653 & 0.069211 & $0 \cdot 312855$ \\
\hline 4. & Naphtha & $\mathrm{EG}^{*}$ & 0.022441 & 0.072267 & $0 \cdot 310529$ \\
\hline 5. & MIBK & $\mathrm{EG}^{*}$ & 0.027836 & 0.089346 & 0.311553 \\
\hline 6. & Kerosene & $\mathrm{EG}^{*}$ & 0.028289 & 0.090852 & 0.311375 \\
\hline 7. & Diesel & EG* & 0.032276 & $0 \cdot 103915$ & $0 \cdot 310600$ \\
\hline 8. & Soap oil & EG* & 0.036422 & 0.116637 & 0.312268 \\
\hline 9. & Xylene & $E G^{*}$ & 0.036623 & 0.116898 & 0.313290 \\
\hline 10. & Benzene & $\mathrm{EG}^{*}$ & 0.038771 & $0 \cdot 124287$ & 0.311947 \\
\hline 11. & Palm oil & EG* & 0.039676 & 0.127986 & $0 \cdot 310003$ \\
\hline 12. & Groundnut oil & EG* & 0.047437 & 0.153134 & 0.309774 \\
\hline 13. & Gingely oil & EG* & 0.048956 & 0.157492 & $0 \cdot 310848$ \\
\hline 14. & Coconut oil & $\mathrm{EG}^{*}$ & 0.049228 & 0.158792 & 0.310016 \\
\hline 15. & Castor oil & EG* & 0.051821 & 0.166917 & 0.310460 \\
\hline 16. & Sandalwood oil & EG* & 0.065139 & 0.209655 & 0.310696 \\
\hline 17. & Heptane & Water & 0.030515 & 0.095982 & 0.317924 \\
\hline 18. & Cyclohexane & Water & 0.039396 & 0.123753 & 0.318344 \\
\hline 19. & Kerosene & Water & 0.044088 & 0.139332 & 0.316424 \\
\hline 20. & Soap oil & Water & 0.063736 & 0.204950 & 0.310983 \\
\hline 21. & Xylene & Water & 0.064060 & 0.206200 & 0.310669 \\
\hline 22. & Turpentine & Water & 0.066707 & 0.209518 & 0.318383 \\
\hline 23. & Toluene & Water & 0.067285 & $0 \cdot 210918$ & 0.319010 \\
\hline 24. & Benzene & Water & 0.072469 & 0.228362 & 0.317343 \\
\hline 25. & Iso-amylacetate & Water & 0.079810 & 0.252024 & 0.316676 \\
\hline 26. & Water & Chlorobenzene & 0.103059 & 0.322714 & 0.319351 \\
\hline \multirow[t]{2}{*}{27.} & Ethylene glycol & Bromobenzene & 0.027260 & 0.086636 & 0.314650 \\
\hline & & & & Mean & 0.313366 \\
\hline
\end{tabular}

*Ethylene glycol; $(r / u), \eta, \rho$ and $(\sigma-\rho)$ from table 2 .

$S=\left[(r / u)^{3 / 2} / \eta^{1 / 2}\right] /\left[\rho^{1 / 2} /(\sigma-\rho)\right]$. 
Table 4. Comparison of density values and estimated error in percentage.

\begin{tabular}{|c|c|c|c|c|}
\hline \multirow[b]{2}{*}{$\begin{array}{l}\text { Sl. } \\
\text { no. }\end{array}$} & \multirow[b]{2}{*}{ Liquid drop } & \multicolumn{2}{|c|}{ Density $\rho\left(\mathrm{kg}^{-3}\right)$} & \multirow{2}{*}{$\begin{array}{c}\text { Estimated } \\
\text { error } \\
(\%)\end{array}$} \\
\hline & & Observed* & $\begin{array}{l}\text { Estimated } \\
\text { from (1) }\end{array}$ & \\
\hline 1. & Hexane & $665 \cdot 12$ & $665 \cdot 77$ & -0.098 \\
\hline 2. & Petrol & $715 \cdot 38$ & 712.98 & 0.335 \\
\hline 3. & Heptane & $720 \cdot 24$ & 719.74 & 0.069 \\
\hline 4. & Naphtha & 733.29 & $730 \cdot 61$ & 0.365 \\
\hline 5. & MIBK & 792.85 & $791 \cdot 32$ & $0 \cdot 193$ \\
\hline 6. & Kerosene & 797.22 & $795 \cdot 56$ & 0.208 \\
\hline 7. & Diesel & 830.65 & $828-53$ & 0.255 \\
\hline 8. & Soap oil & 857.01 & $856 \cdot 24$ & 0.090 \\
\hline 9. & Xylene & 857.50 & $857 \cdot 44$ & 0.007 \\
\hline 10. & Benzene & $870 \cdot 60$ & 869.65 & $0 \cdot 109$ \\
\hline 11. & Palm oil & 876.66 & 874.45 & $0 \cdot 254$ \\
\hline 12. & Groundnut oil & $910 \cdot 91$ & $908 \cdot 85$ & 0.226 \\
\hline 13. & Gingely oil & 915.85 & 914.44 & $0 \cdot 154$ \\
\hline 14. & Coconut oil & $917 \cdot 27$ & 915.41 & 0.203 \\
\hline 15. & Castor oil & $925 \cdot 72$ & $924 \cdot 17$ & 0.167 \\
\hline 16. & Sandalwood oil & $960 \cdot 20$ & 959.02 & 0.123 \\
\hline 17. & Heptane & $720 \cdot 37$ & 723.73 & -0.466 \\
\hline 18. & Cyclohexane & 775.04 & $778 \cdot 12$ & -0.397 \\
\hline 19. & Kerosene & $797 \cdot 34$ & 799.08 & -0.218 \\
\hline 20. & Soap oil & $857 \cdot 15$ & $856 \cdot 14$ & 0.118 \\
\hline 21. & Xylene & 857.95 & $856 \cdot 14$ & $0 \cdot 133$ \\
\hline 22. & Turpentine & $860 \cdot 03$ & 862.07 & -0.237 \\
\hline 23. & Toluene & $860 \cdot 89$ & 863.17 & -0.265 \\
\hline 24. & Benzene & 870.78 & 872.29 & -0.173 \\
\hline 25. & Iso-amylacetate & $882 \cdot 15$ & 883.31 & -0.131 \\
\hline 26. & Water & $1000 \cdot 00$ & $1001 \cdot 75$ & $-0 \cdot 175$ \\
\hline 27. & Ethylene glycol & 1108.00 & $1109 \cdot 33$ & -0.120 \\
\hline
\end{tabular}

*From table 2 .

liquid samples in small quantities for identification and confirmation through other analytical means apart from density determination.

Since the measurement of weight of the liquid drop is not involved in this method, the availability of a high precision balance is not an essential requirement as in the case of other conventional methods viz: specific gravity bottle method, pyknometer method, Westphalbalance method (Serence et al 1970; O'Hara and Osterburg 1974; Giancoli 1984) etc for getting the accurate density value, and hence this method may be employed in any operational laboratory where high precision and expensive equipment is not available for accurate weighing.
The added advantage of this method is that the liquid drop injected at the bottom can be retrieved from the top of the liquid column using a micro-syringe or filter paper for further analysis as the drop liquid and the column liquid are immiscible.

\section{Conclusion}

This method may be employed to determine the density of liquids available in small or micro-quantities and also provides a practical alternative to other conventional methods. The authors do not suggest that this approach is an acceptable substitute for those liquids which do not have any suitable column liquid. Therefore, the column liquid should be selected in such a way that it is immiscible with as well as denser than the liquid to be tested.

\section{References}

Bhattacharya S P and Venkateswarlu D 1957 Trans. Indian Inst. Chem. Engrs. 1025

Clift R, Grace J R and Weber M E 1978 Bubbles, drops and particles (New York: Academic Press)

Davis R E and Acrivos A 1966 Chem. Eng. Sci. 26681

Giancoli D C 1984 General physics (New Jersey: Prentice Hall Inc)

Goldsmith H L and Mason S G 1962 J. Fluid. Mech. 14 42

Grace J R, Wairegi T and Nguyen T H 1976 Trans. Inst. Chem. Eng. 54167

Griffith R M 1962 Chem. Eng. Sci. 171057

Harmathy T Z 1960 Aiche. J. 6281

Houghton G, Ritchie P D and Thomson J A 1957 Chem. Eng. Sci. 7111

Klee A J and Treybal R E 1956 Aiche. J. 2444

O'Hara C E and Osterburg I W 1974 An introduction to criminalistics (London: Indiana University Press)

Saffman P G 1956 J. Fluid Mech. 1249

Serence Jr M, Lemon H B and Stephenson R J 1970 Analytical experimental physics (London: The University of Chicago Press)

Srinivasan G J, Satyanarayana P and Thirunavukkarasu G 1996 Curr. Sci. 71989

Zieminski S A and Raymond D R 1968 Chem. Eng. Sci. 23 17 